Forthcoming with Philosophy and Phenomenological Research. Please cite published version.

\title{
OTHER-SACRIFICING OPTIONS*
}

\author{
Benjamin Lange \\ St. Anne's College, University of Oxford
}

\begin{abstract}
I argue that you can be permitted to discount the interests of your adversaries even though doing so would be impartially suboptimal. This means that, in addition to the kinds of moral options that the literature traditionally recognises, there exist what I call other-sacrificing options. I explore the idea that you cannot discount the interests of your adversaries as much as you can favour the interests of your intimates; if this is correct, then there is an asymmetry between negative partiality toward your adversaries and positive partiality toward your intimates.
\end{abstract}

Keywords: Moral Options, Common-Sense Morality, Other-Sacrificing, Negative Partiality, Self-Other Asymmetry, Other-Favouring, Symmetry, Moral Space, Partiality, Agent-centred Prerogatives, Permissions

\footnotetext{
* I'm grateful to Bastian Stern, Kacper Kowalczyk, Stefan Riedener, Susanne Burri, and Tomi Francis for feedback as well as an anonymous referee for highly perceptive and encouraging comments on previous drafts. Special thanks to Ralf Bader and Roger Crisp for extensive discussion.
} 


\section{Introduction}

Common-sense morality denies that you are always required to do what is best from an impartial point of view. According to one interpretation of this postulate, this means that you have

Agent-Centred Moral Options (henceforth just "options"): A permission to bring about an outcome that is impartially suboptimal because it promotes your own or your intimates' interests. ${ }^{1}$

This interpretation of options maintains that you can sometimes permissibly do what is impartially suboptimal, but you are not required to do it- that is, you are still permitted to do what is impartially best. Many people believe that options of this sort exist, but they are tricky to defend. ${ }^{2}$ Much debate has consequently focused on how, and if at all, different moral theories can accommodate them. ${ }^{3}$

This paper argues that matters are even more complicated than has previously been recognised. I defend a new kind of option which I call an

Other-Sacrificing Option: A permission to bring about an impartially suboptimal outcome because it discounts your adversaries' interests.

Your adversaries are those with whom you stand in a morally negative personal relationship. This relationship is constituted by a morally significant history of negative interactions. If you have a choice between giving a moderate benefit to your adversary

\footnotetext{
${ }^{1}$ Scheffler (1982) calls these options "agent-centred prerogatives". The difference is only terminological. I follow Kagan (1989), pp. 6-10, and understand "interests" here broadly as opposed to narrowly in terms of pure self-concern.

${ }^{2}$ Kagan (1989) argues at length that options cannot plausibly be defended.

${ }^{3}$ The locus classicus for a defence of an agent-centred prerogative is Scheffler (1982). Other defences of options, though by no means exhaustive, are Sider (1993), Portmore (2003; 2008), and Bader (forthcoming).
} 
or a comparatively smaller benefit to a stranger, I argue that you can be permitted to benefit the stranger.

I defend other-sacrificing as follows. Sections 2 and 3 each give an argument for the permissibility of other-sacrificing: an intuitive argument and a symmetry argument. Section 4 considers the relation between other-favouring and other-sacrificing options. I explore a view according to which you cannot discount the interests of your adversaries as much as you can favour the interests of your intimates. Section 5 concludes by examining two of the most promising approaches for justifying options. I find that only one of them has the resources to account for the evolution of your permitted other-favouring and other-sacrificing in moral space.

\section{The Intuitive Argument}

Suppose that in

Intimate vs. You. ${ }^{4}$ You can either

1. Benefit your intimate by 1 ; or

2. Benefit yourself by 5 .

If you have a choice between providing a small benefit to an intimate or a moderately greater benefit to yourself, impartial consequentialism says that you must give the benefit to yourself, because this will bring about the most good. Common sense morality

\footnotetext{
${ }^{4}$ Most of the cases that will be considered in what follows are abstract, but nonetheless informative. I focus on outcomes and make simplifying assumptions about the means by which you might be helping or burdening people. I understand the bestowing of benefits as including the prevention of evils, assume that prospective benefits and burdens are unowned, and set aside issues to do with the exact causal-structure of the provision of benefits and burdens in question.
} 
disagrees. It says that you can permissibly give less weight to your own good and give the small benefit to your intimate. However, you are generally not required to do so. Put more abstractly, some think that since it is permissible to give the smaller benefit to your intimate in Intimate vs. You, you have a

Self-Sacrificing Option ${ }^{5}$ : A permission to bring about an impartially suboptimal outcome because it discounts your own interests.

Suppose next that in

Intimate vs. Intimate. You can either

1. Benefit one of your intimates by 1 ; or

2. Benefit another intimate by 5 .

If you have a choice between providing a small benefit to one of your intimates or a moderately greater benefit to another intimate, who is equally dear to you, many think that you may not permissibly give your intimate the lesser benefit. You are required to give the greater benefit to the second intimate.

These two cases are in some respects parallel, yet your permissions differ. The benefits that you can provide in each case are the same, but you may only permissibly choose to forgo the provision of the greater benefit in Intimate vs. You. A natural explanation for this difference is the fact that in Intimate vs. You you face the choice of sacrificing your own good whereas in Intimate vs. Intimate you face the choice of sacrificing the greater good of someone else, namely of one of your intimates. ${ }^{6} \mathrm{We}$ might therefore conclude that there exists a morally significant Self-/Other Asymmetry.

\footnotetext{
${ }^{5}$ Stocker (1976) first noted the existence of this option. See also Slote (1984; 1985). For a detailed discussion of the relation between self-sacrificing options and options to favour your own interests, see Hurka and Shubert (2012).

${ }^{6}$ For an argument why consent is not a relevant explanation, see Stocker (1976), pp. $210-$ 12, and Slote (1984), pp. 190-1.
} 
Many think that the Self-/Other Asymmetry categorically rules out the permissibility of other-sacrificing. Douglas Portmore expresses this point as follows:

\begin{abstract}
"On common-sense morality, there is an asymmetry between what an agent is permitted to do to herself and what she is permitted to do to others (hence, the name): specifically, whereas it is permissible for an agent to sacrifice her own greater good for the sake of providing others with some lesser net benefit, it is not permissible for an agent to sacrifice someone else's greater good (even with her permission) for the sake of providing yet others with some lesser net benefit."
\end{abstract}

This claim is false. Though other-sacrificing is impermissible in Intimate vs. Intimate, it does not follow that it is always impermissible. It can be permissible within the domain concerned with partiality to your adversaries as opposed to your intimates.

To recognise this domain, suppose that you conceive of yourself and your personal relationships as existing in a kind of moral space. ${ }^{8}$ You are closest to yourself. The distance between you and someone else-but not necessarily between you and yourself - is a function of the personal relationship that you have with them. ${ }^{9}$ Among other variables, this function may include the nature of your personal relationship interactions, the intensity of your relationship, and whether your relationship is one-directional or reciprocal. Your intimates such as your family members or friends are closer to you in moral space than strangers by virtue of the positive personal relationship that

\footnotetext{
${ }^{7}$ Portmore (2008), p. 411. This asymmetry was first introduced by Stocker (1976), section 2, and later more extensively explored by Slote (1985), ch. 1. See also Sider (1993).

${ }^{8}$ Broad (1942), p. 55, has alluded to moral space in the context of special obligations and Bader (2016; forthcoming) provides a more explicit account of moral space. Nozick (1974), p. 57, has written about moral space in the slightly different context of moral rights.

${ }^{9}$ For simplicity, I here assume that the totality of facts of how people relate to one another determines net moral distance. This leaves open the possibility of multidimensional accounts of moral space, which would allow for "frenemy" relationships-i.e. relationships with people who are a dear intimate and bitter adversary in equal respects.
} 
you have with them. Your positive personal relationships are constituted by histories of various forms of morally significant positive encounters.

Strangers represent a morally neutral midpoint. They represent how much you should promote their interests independent of any personal relationships that you have with them.

If your intimates are the ones located closer to you in moral space, then there can also be people who are morally distant from you - that is, located farther away from you than strangers. These people are your adversaries. They are more distant from you than strangers by virtue of your negative personal relationship with them. Your negative personal relationships are constituted by histories of various morally significant negative encounters.

\section{Illustration 1. Distance in Moral Space}

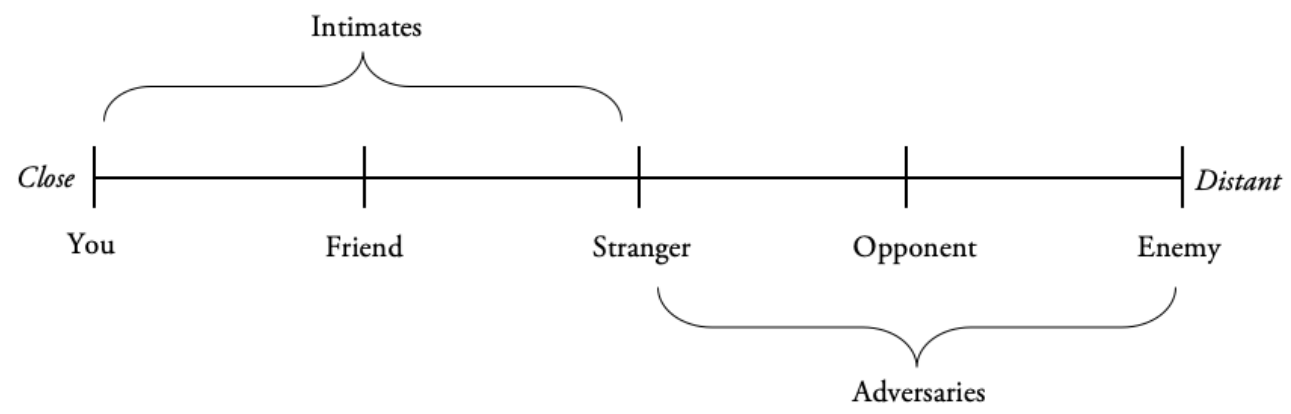

Other-sacrificing is impermissible when you are concerned with bestowing benefits on your intimates. However, other-sacrificing can be permissible when you are concerned with bestowing benefits on your adversaries.

Suppose that in

Stranger vs. Adversary. You can either

1. Benefit a stranger by 1 ; or

2. Benefit your adversary by 5 . 
This case is parallel to Intimate vs. Intimate except that your personal relationship to some of your beneficiaries has changed. Whereas you previously had the choice of sacrificing the good of your intimates with whom you stood in a morally positive relationship, you now face the prospect of sacrificing the good of your adversaries for someone with whom you stand in a morally neutral personal relationship.

The fact that you stand in a morally negative personal relationship with your adversaries is morally significant. It can render it permissible for you to discount the benefits that you can give them. We may think that you are therefore permitted to give the lesser benefit to the stranger in Stranger vs. Adversary.

Here is a vignette that lends colour to Stranger vs. Adversary and elicits the normatively significant factors that characterise adversarial personal relationships and justify an other-sacrificing response:

Callous Colleague: Imagine that Ann's co-worker Beth has recently been very mean to her with no justified cause. Ann has tried talking to Beth about them having gotten off on the wrong foot, but Beth has not shown any willingness to change. Suppose now that Beth could really use Ann's help with preparing a document for an upcoming meeting, a favour that Ann could grant Beth easily by having a chat with her, hence making her very happy. However, suppose that Ann could also instead help her new co-worker Chloe with preparing a document for her first weekly report. For this she would have to have an equally long chat with her. This would make Chloe happy, though not quite as much as Beth receiving Ann's help. Further, suppose that Chloe herself has also had a rough start at her new workplace and has been mean to almost all of her new colleagues except Ann, who she has not met yet.

Assuming that Ann must make a choice to help either Beth or Chloe, that the cost of helping both in the form of a short clarifying conversation is the same, and that Beth and Chloe have been equally mean to people in the past, is Ann permitted to give less 
weight to the prospectively greater benefit that she could give to Beth and instead help Chloe?

Intuitively, it seems that Ann is indeed permitted to discount the interest of Beth by virtue of their history of negative interactions. Though, for example, a single act of needlessly failing to approve Ann's admin request or unduly criticising Ann's work may not overall justify a discounting response with notable practical upshots, a history of these negative acts becomes more noticeably normatively significant. ${ }^{10}$ The fact that Beth fails to adjust her behaviour upon being repeatedly confronted by Ann creates a morally negative personal relationship that is constituted by a history of acts of hindering, ingratitude, as well as a lack of cooperation.

However, though Ann's other-sacrificing response is reasonable, it does seem like an intuitive stretch to assert that Ann is required to provide her adversary with the lesser benefit. We might think that though there is something morally admirable about their choosing not to act on their other-sacrificing permission, to suggest that it would be wrong if they chose to do so is implausible. You are never required to sacrifice the interests of your adversaries.

It is worth clarifying that Ann has a distinctively agent-relative as opposed to agentneutral response to discount the prospective benefit that she could bestow on Beth -

\footnotetext{
${ }^{10}$ See Kolodny (2010) for an attempt to explain the normative significance of historical interactions by appeal to a resonance principle. In his discussion of negative partiality, he argues that morally negative personal relationships can never justify a retaliatory response in the form of harming your adversary (pp. 186-9). This claim is consistent with (though not necessarily implied by) my view in this discussion, since I defend a permission to discount as opposed to harm an individual with whom you have a negative personal relationship. I consider the conditions under which other-sacrificing options may imply a permission to burden your adversaries at the end of section 4 .
} 
it is a justified response for Ann, but not necessarily for anyone one else. ${ }^{11}$ For example, it is not fully explained by the fact that Beth morally deserves to be treated less favourably considered from an impartial point of view. Explaining the permissible discounting of your adversaries' interests entirely by appeal to the fact that they are impartially less deserving of being benefitted is as implausible as attempting to explain the permissible favouring of your intimates' interests by appeal to them being more deserving of being benefitted. Neither positive partiality to your intimates nor negative partiality to your adversaries is entirely reducible to agent-neutral considerations such as moral desert.

\section{The Symmetry Argument}

The previous section made the intuitive case for other-sacrificing options. But we can say more to support their existence: We can appeal to reasons of symmetry. If symmetry considerations lead us from independently plausible phenomenon $A$ to some other phenomenon $B$, then this provides some evidence for the plausibility of phenomenon $B$.

There exist two ways to conceptualise the various types of suboptimal behaviour that common-sense morality typically countenances. I here do not commit to either conception. My aim is merely to show that both of them allow us to appeal to symmetry considerations to derive the permissibility of other-sacrificing, and, more problematically, perhaps even the requirement to do so.

Here is the first picture. According to what we can call the

\footnotetext{
${ }^{11}$ Neither is Beth permitted to discount Ann's interests. Ann can discount Beth's interests but not vice versa since Ann does not mirror Beth's negative behaviour. More generally, this illustrates that morally negative personal relationships can be asymmetrical: You are not necessarily your adversary's adversary.
} 
List Picture, impartially suboptimal behaviour should be understood in terms of a list of different permissions. ${ }^{12}$

On this view, there exists a list of different kinds of options, based on who enjoys the benefits or suffers the burdens—oneself, or others.

That is, the fact that common-sense morality sometimes allows you to give more weight to your interests than the interests of strangers is understood in the form of

Self-Favouring Option ${ }^{13}$ : A permission to bring about an impartially suboptimal outcome because it favours your own interests.

And the fact that you are sometimes allowed to give more weight to the interests of your intimates than to the interests of strangers, is accordingly understood as an

Other-Favouring Option: A permission to bring about an impartially suboptimal outcome because it favours your intimates' interests.

We can illustrate the List Picture as follows:

Table 1. List Picture of Moral Options

Focal point / Response type Favouring Sacrificing

\begin{tabular}{c|cc} 
Self- & Self-Favouring Option & Self-Sacrificing Option \\
Other- & Other-Favouring Option & $?$
\end{tabular}

(Needless to say, I think an other-sacrificing option belongs into the bottom-right cell and should be added to the list.)

${ }^{12}$ This is by far the most common picture of options. Theorists that rely on this picture are Kagan (1989), Scheffler (1982), Sider (1993), and Portmore (2006; 2008).

${ }^{13}$ Early discussions of this permission are in Parfit (1977), Davis (1980), and Scheffler (1982). 
We can hold a different view. Here is the second picture of options. According to what we can call the

Agent-Neutral/Relative Picture, impartially suboptimal behaviour should be understood in terms of permissibly acting from an agent-relative point of view. ${ }^{14}$

This picture understands options as a permission to take on and act from an agentrelative perspective that is sensitive to moral closeness facts. You can centre this perspective on the person who is acting (agent) or the person who is being acted upon (patient). If you centre this perspective on yourself when you are concerned with benefitting your intimates, then their interests will matter more to you by virtue of the shorter moral distance between you and them. This can render it permissible for you to favour your intimates' interests over those of strangers even if this brings a suboptimal outcome from the agent-neutral perspective. The agent-neutral perspective abstracts from any particular perspective.

The contrast with the List Picture becomes more apparent by considering the following illustration:

Table 2. Agent- Neutral/Relative Picture of Moral Options

Focal Point / Close (Favouring) Unmodified Distant (Discounting)
Modification

\begin{tabular}{l|ll}
\hline Agent-Neutral & & Impartiality \\
Agent-Relative & $\begin{array}{cc}\text { Positive Partiality } \\
\text { (oneself and others) }\end{array}$ & Peutral \\
& & Partiality
\end{tabular}

${ }^{14}$ Kamm (1992), pp. 362-3, seems to allude to this kind of picture. Bader (forthcoming), section 3, endorses it explicitly. 
In contrast to the List Picture that stipulates different kinds of options, this picture understands the various ways to engage in suboptimal behaviour in a unified fashion as acting from an agent-relative perspective. For example, the option to sacrifice your own interests for an intimate may be understood as your taking on the perspective of that intimate and favouring their interests from their own agent-relative point of view. ${ }^{15}$

This means that according to this picture there only exists what we might call an

Agent-Relative-Favouring Option: A permission to bring about an impartially suboptimal outcome because it favours your own or your intimates' interests from the agent-relative perspective.

It is irrelevant for our purposes which of these two pictures of options is correct. Reasons of symmetry support the permissibility of other-sacrificing on either of them. Other-sacrificing options can be understood as the negative mirror image of the otherfavouring and agent-relative-favouring option. We can see this by making explicit the negative counterparts of the constitutive elements of both options. Once we do this, we will end up with an other-sacrificing option.

\section{Illustration 2. Negative Mirror of Other-Favouring}

${ }^{15}$ Though the Agent-Neutral/Relative Picture could construe self-sacrificing options as a form of patient-self-favouring, it is another matter whether it should; see Bader (forthcoming), section 6 , for a discussion of the problems involved in doing so.

There is also a more general worry. As Slote (1984), p. 185, observes, despite their intuitive appeal, self-sacrificing options appear antithetical to the idea that moral closeness increases your options to favour. Some may take this tension to reinforce the plausibility of the List Picture-which need not ascribe ultimate explanatory significance to moral closeness factswhereas others might see it as reason to be sceptical about the existence of self-sacrificing options altogether. I flag, but do not settle this issue here. 


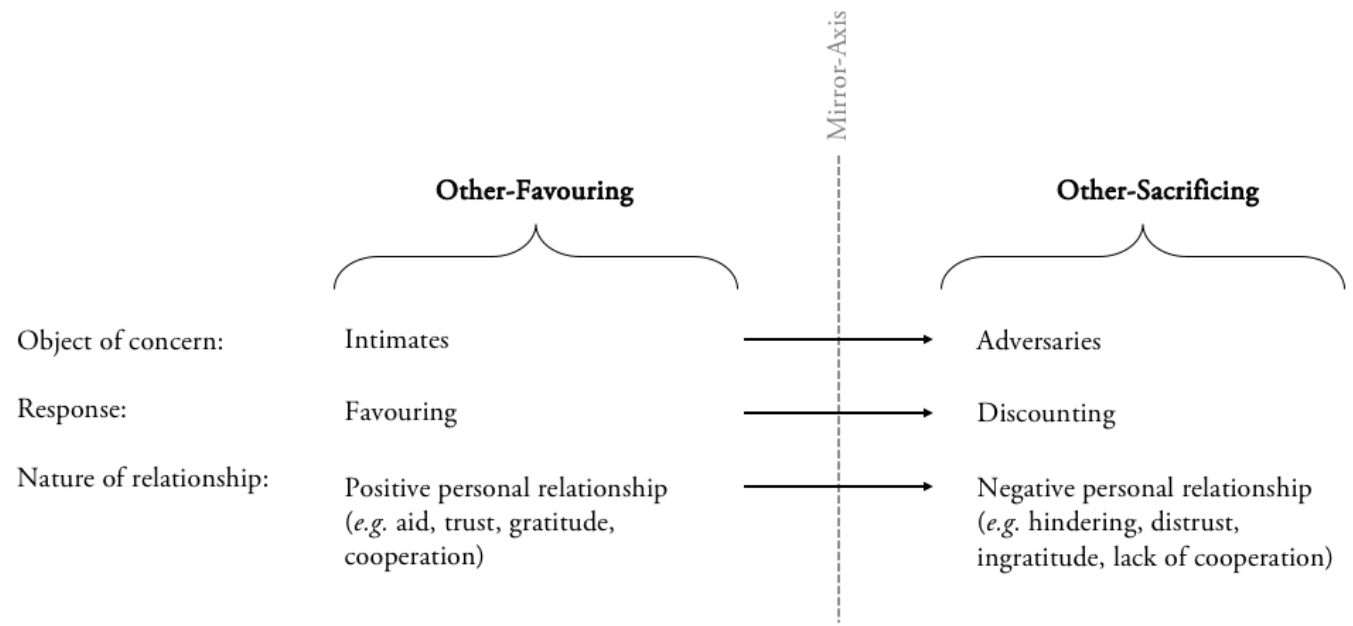

Other-favouring and agent-relative favouring options are forms of positive partiality to your intimates. You are permitted to favour the interests of your intimates over those of strangers by virtue of your positive personal relationships with them. Positive relationships with your intimates include normatively significant histories of interactions of, for example, aid, trust, gratitude, or cooperation, whereas your relationships with strangers, or rather the absence thereof, lack such a history. ${ }^{16}$ As a result of your positive relationships with your intimates, they are morally closer to you than strangers, and you are permitted to favour them.

If there can be permissible positive partiality to your intimates, then symmetry suggests that there can also be permissible negative partiality to your adversaries. The permissible attitude to take toward your adversaries is the negative mirror of the permissible attitude that you can take toward your intimates. This means that you are permitted to discount as opposed to favour the interests of your adversaries. The ground of your

\footnotetext{
${ }^{16} \mathrm{I}$ 'm not claiming that all positive personal relationships are constituted by these kinds of interactions. For example, the parent-child relationship is structurally very different from the relationship between friends and characterised by distinctive interactions. See Lange (manuscript-a) for a discussion of permissible parental partiality. My claim is only that, insofar as there exist certain positive interactions that constitute positive personal relationships, they have negative counterparts.
} 
permission to discount your adversaries is the negative mirror of the ground of your permission to favour your intimates. If you are permitted to favour your intimates by virtue of your positive personal relationships with them, then you are permitted to discount your adversaries by virtue of your negative personal relationships with them. The constitutive elements of your negative personal relationships with your adversaries are the negative mirror of the constitutive elements of your personal relationships with your intimates. Negative relationships can be characterised by normatively significant interactions of, for example, hindering, distrust, ingratitude, and lack of cooperation. We might now wonder: If reasons of symmetry can lead us from other-favouring to other-sacrificing options, can symmetry also lead us from duties to favour your intimates over strangers to duties to discount your adversaries? ${ }^{17}$ I previously suggested that requirements to discount your adversaries are intuitively implausible. However, symmetry seems to imply their existence.

Whether this is so depends on our picture of options. I have here characterised the List Picture as only concerned with different kinds of options, but we might think that it naturally lends itself to a more encompassing interpretation: one that also includes duties of positive partiality to your intimates. If this is correct, then it seems natural to think that the List Picture should add duties to discount your adversaries—-the negative mirror of positive duties of partiality to favour your intimates- to its list.

By contrast, the Agent-Neutral/Relative Picture cannot, at the same time, both imply the existence of other-sacrificing options as well as other-sacrificing duties. According to the interpretation of the picture that I have given here, you always have the choice to act from the agent-relative perspective, but you do not have to do it. This interpretation of the picture can therefore not generate duties of partiality-positive or negative-at all. ${ }^{18}$ According to a second interpretation, you are always required to act from

\footnotetext{
${ }^{17}$ I'm grateful to an anonymous referee for encouraging me to explore this idea in more detail.

${ }^{18}$ This is Bader's view (forthcoming).
} 
your agent-relative perspective, perhaps precisely because it is your perspective. This interpretation implies the existence of certain kinds of duties of partiality, including duties to favour your intimates over strangers and, by appeal to symmetry, duties to discount your adversaries. However, it cannot account for options.

So, either we get both other-sacrificing options and duties (List Picture), only options, but no duties of positive partiality ( $1^{\text {st }}$ interpretation Agent-Neutral/Relative Picture), or no options and only duties of partiality $\left(2^{\text {nd }}\right.$ interpretation Agent-Neutral/Relative Picture). None of these possibilities seems entirely satisfactory.

\section{The Fabric of Other-Sacrificing}

If you are permitted to discount the interests of your adversaries, to what extent can you discount them? Is negative partiality to your adversaries the negative mirror of positive partiality to your intimates?

We can make more headway on these questions by reflecting on the relation between the evolution of the degree of your permitted other-favouring and other-sacrificing options through varying distance in moral space. ${ }^{19}$

First, imagine that in

Stranger vs. Close Intimate. You can either

1. Benefit a stranger by 5 ; or

${ }^{19}$ There is an alternative to reflecting on your permitted other-favouring and other-sacrificing at this coarse-grained level of partiality. We can also examine how the constitutive elements and nature of positive and negative personal relationships influence your permitted other-favouring and other-sacrificing. For example, we might think that reciprocal positive personal relationships increase your permitted other-favouring whereas reciprocal negative personal relationships decrease your permitted other-sacrificing, perhaps even to the point of permitting no discounting at all. See Lange (manuscript-b) for a fine-grained analysis of this sort. 
2. Benefit your close intimate by 1 .

If you can give a small benefit to your intimate or a moderately greater benefit to a stranger, intuitively it seems that you can permissibly care more about your close intimate and benefit them as opposed to the stranger. However, it seems intuitively implausible that you can favour their interests a whole lot more over those of strangers. If the prospective benefit to the stranger becomes large enough, you will be required to benefit them instead. Suppose that you are permitted to favour your close intimate by a ratio of 1:5 and give them the comparably lesser benefit.

Suppose now that in

Stranger vs. Very Close Intimate. You can either

1. Benefit a stranger by 10 ; or

2. Benefit your very close intimate by $1 .^{20}$

If you have a choice between giving a small benefit to your very close intimate or a much larger benefit to a stranger, we might think that you can permissibly benefit your intimate.

This seems intuitively plausible. You are permitted to favour the interests of your recent acquaintance whom you met at a dinner party to some degree, but you are surely permitted to favour the interests of your very good friend whom you have known since your childhood more. Your permitted other-favouring might consequently increase as the moral distance between you and your intimates decreases as shown in the following illustration.

\footnotetext{
${ }^{20}$ For clarification: I assume that the pairs of "close intimate" and "distant adversary" and "very close intimate" and "very distant adversary" are negative mirrors in moral space respectively.
} 


\section{Illustration 3. Evolution of Permitted Other-Favouring $\mathrm{I}^{21}$}

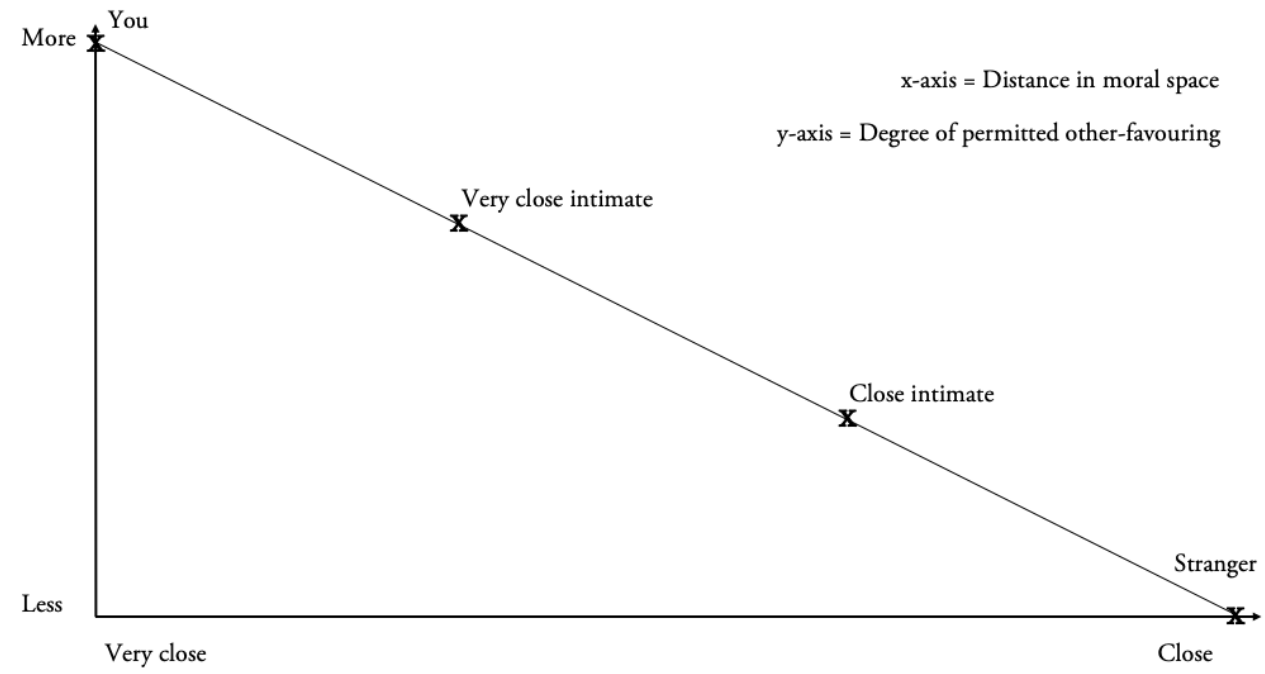

In a nutshell: you can favour your intimates more, the closer they are to you.

Some might be drawn towards a more nuanced view. Suppose that in

Stranger vs. Very Close Intimate*. You can either

1. Benefit a stranger by 9; or

2. Benefit your very close intimate by 1 .

We might think that even though you can favour your friends more the closer they are to you, you cannot favour a very close intimate twice as much as a close intimate. Accordingly, the evolution of your permitted other-favouring might look more like one of the two dotted lines as shown in this graph:

\section{Illustration 4. Evolution of Permitted Other-Favouring II}

${ }^{21}$ The illustrations in this section are intended as rough visualizations of what is said in words. They do not purport to offer precise mathematical quantifications of moral space or degrees of favouring/sacrificing. 


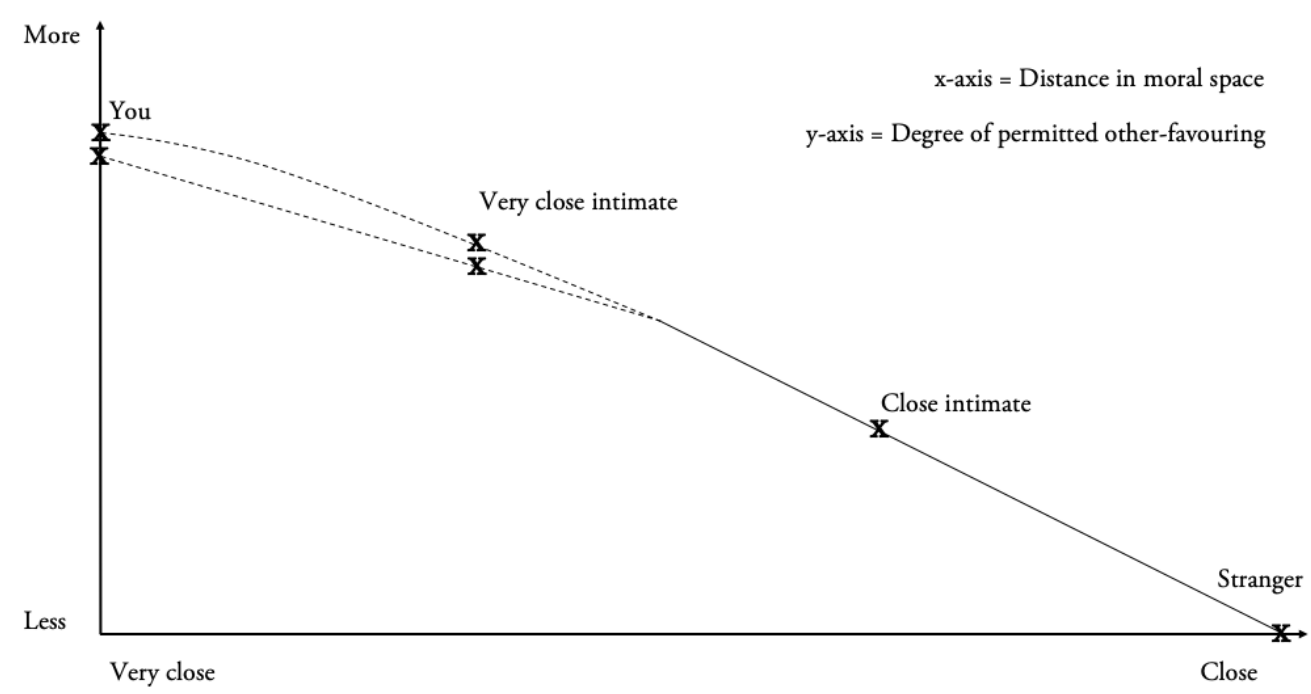

Once your dinner party acquaintance turns into a good friend of yours, you will be increasingly permitted but also required to favour their interests.

Let's consider other-sacrificing. Suppose that in

Stranger vs. Distant Adversary. You can either

1. Benefit a stranger by 1 ; or

2. Benefit your distant adversary by 5 .

If you have a choice between giving a small benefit to a stranger or a slightly greater benefit to your distant adversary, we might think that you are permitted to benefit the stranger instead. If you think that this view is correct, then you believe that you can favour your intimates as much as you can discount your adversaries.

Though theoretically neat, this view may seem counterintuitive to some. Consider two personal relationships that are exact negative counterparts of each other: a morally positive personal relationship with your recent friend that you have met at a dinner party and a morally negative personal relationship with a recent bully that you have made at another dinner party and who has been nasty to you. Intuitively, there is some 
pull to say that though it is permissible to favour your intimate's interests, it is impermissible to discount those of your adversary. You are permitted to bring your recent friend medicine that will alleviate their mild headache as opposed to give your newlymoved-in neighbour some other medicine that will cure their severe cold; however, you are not permitted to alleviate your new neighbour's mild headache instead of providing your recent bully with a medicine to cure their severe cold. ${ }^{22}$

If you think that these considerations have some persuasive force, then you think that you are not permitted discount your adversaries' interests as much as you can favour your intimates'. Accordingly, we might think that although you can favour your intimates' interests by a ratio of $1: 5$, you are not permitted to discount an adversary to the same degree. You are only permitted to discount them by less-let's assume by a ratio of $1: 4$.

Suppose now that in

Stranger vs. Very Distant Adversary. You can either

1. Benefit a stranger by 1 ; or

2. Benefit your very distant adversary by 8 .

If the ratio whereby you can discount all of your adversaries is $1: 4$, then you may permissibly give a small benefit to the stranger as opposed to a moderately greater benefit to your very distant adversary. This is because the moral distance between you and your adversary will have increased and the distance between you and the stranger will have remained unchanged. We can illustrate the above considerations about your permitted other-favouring again by a graph.

\section{Illustration 5. Evolution of Permitted Other-Sacrificing I}

\footnotetext{
${ }^{22}$ What explains the intuitive pull that when all things are equal—at level of partialityyou are permitted more favouring of your intimates than discounting of your adversaries is a very difficult question. I attempt to explore it in more detail in Lange (manuscript-b).
} 


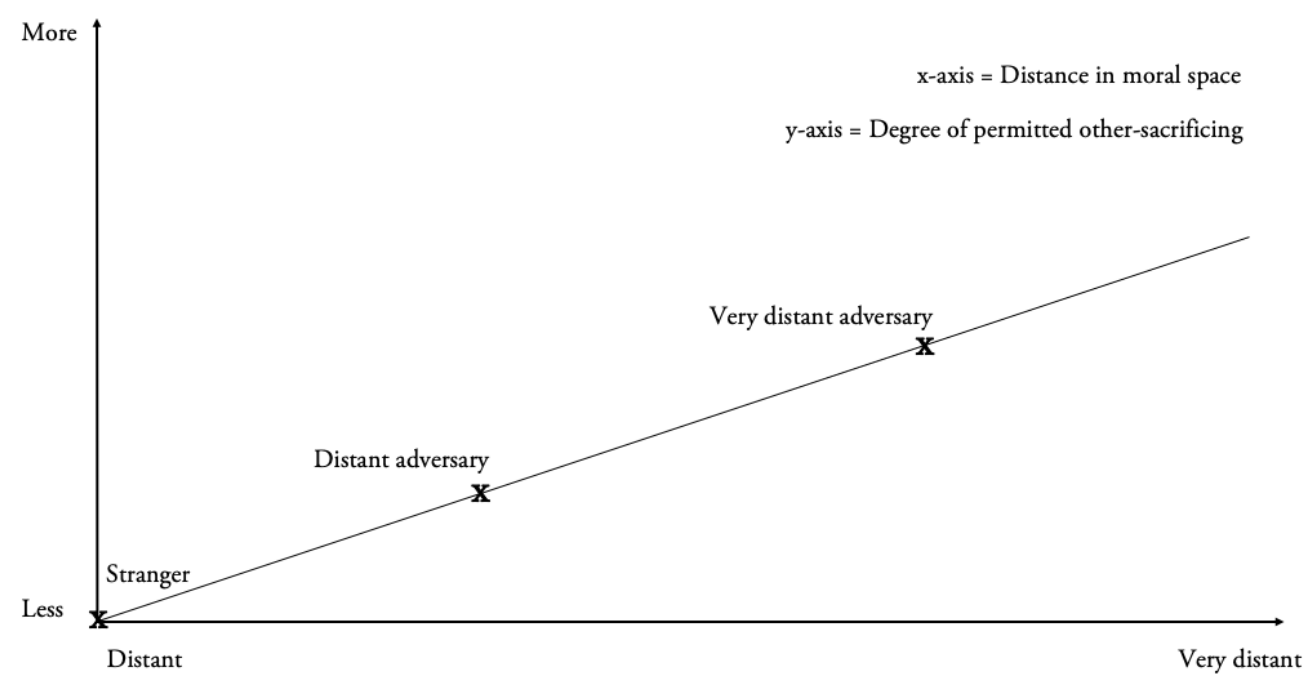

In contrast to the slope that shows your permitted other-favouring (Illustration 3), the slope of this function of the evolution of your permitted other-sacrificing is less steep. As with the evolution of your permitted other-favouring, there exists a more nuanced view that we can hold. Imagine that in

Stranger vs. Very Distant Adversary*. You can either

1. Benefit a stranger by 1 ; or

2. Benefit your very distant adversary by 7 .

We might think that even though you can discount your adversaries more the more of an adversary they are for you, the degree to which you can discount them decreases as they move farther away from you in moral space.

We can now ask: Does the decrease in your permitted other-sacrificing mirror the decrease in your permitted other-favouring? Intuitively, the answer is No. Consider

Stranger vs. Very Distant Adversary**. You can either

1. Benefit a stranger by 1 ; or

2. Benefit your very distant adversary by 6 . 
We might think that not only the degree to which you discount your adversaries decreases the more of an adversary they are for you, but that this decrease in the degree of extensiveness is greater than the corresponding decrease in the extensiveness of your other-favouring permissions. This is the most nuanced view and allows for the least amount of other-sacrificing.

\section{Illustration 6. Evolution of Permitted Other-Sacrificing II}

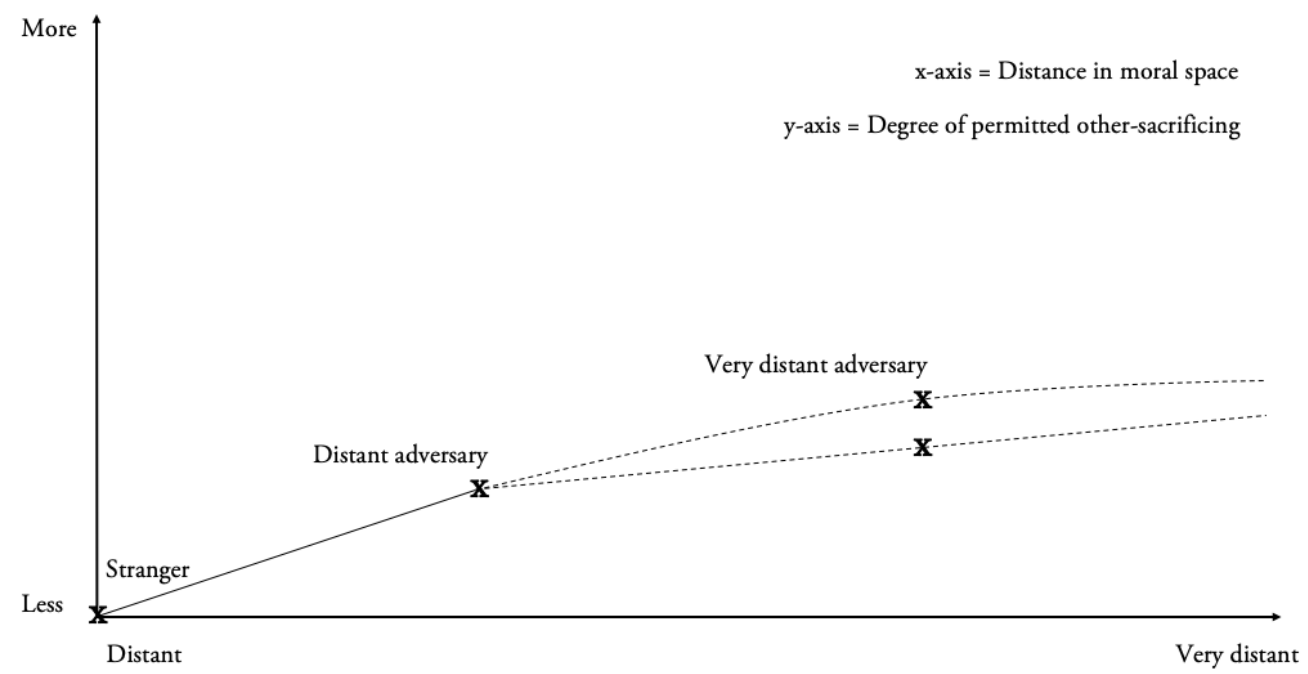

Accordingly, the slope that models the evolution of your permitted other-sacrificing could be either more more concave or less steep than the slope of the other-favouring counterpart.

The foregoing considerations about the relation between the evolution of the extensiveness of other-favouring and other-sacrificing options can be summarised more concisely as follows:

\section{Illustration 7. Other-Favouring/Sacrificing Asymmetry}




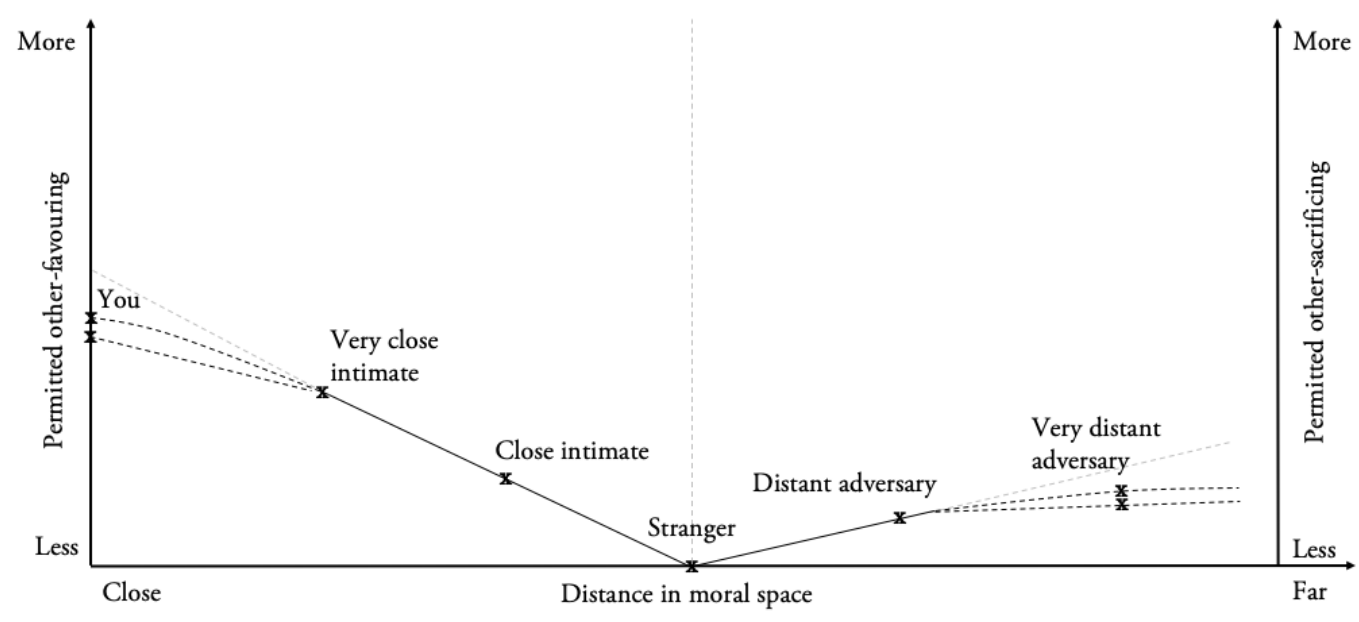

Other-Favouring/Sacrificing Asymmetry: The greater the moral distance between you and your intimates, the less you are permitted to favour them. The smaller the distance between you and your adversaries, the less you are permitted to discount them. As the moral distance between you and your intimates decreases and the distance between you and your adversaries increases, your other-favouring options increase to a greater degree than your other-sacrificing options.

This phenomenon is the analogue of an evolution between your permitted self-favouring and self-sacrificing through decreasing moral space. ${ }^{23}$

${ }^{23}$ Specifically, symmetry suggests that the greater the distance in moral space between you and your intimates, the more you are permitted to sacrifice yourself and the more you are permitted to favour yourself. As the moral distance between you and your intimates decreases, your self-sacrificing options decrease to a lesser degree than your self-favouring options.

Insofar as this self-favouring/sacrificing asymmetry is plausible, it provides credibility for what we have observed in this section about the relation between other-favouring and othersacrificing options.

However, some will find this asymmetry more plausible than others. Hurka and Shubert (2012) maintain that you are permitted more self-sacrificing with your intimates than with strangers, Bader (forthcoming) maintains that you are permitted more self-sacrificing with 
We have explored a view according to which you are not permitted to discount your adversaries as much as you can favour your intimates. But what if the distance between you and your adversary becomes very large indeed?

In moral space, you are the ultimate intimate, but there is no ultimate adversary and therefore no limit to the distance that can exist between you and your adversaries. Suppose that in

Stranger vs. Arch-Enemy. ${ }^{24}$ You can either

1. Benefit a stranger by 1 ; or

2. Burden your arch-enemy by 5 .

If you have a choice between providing a small benefit to a stranger and countenancing a moderate burden to a very distant adversary — and the distance between you and the adversary is sufficiently large-it seems that it can become permissible to burden your adversary as opposed to benefit a stranger. For you will be permitted to discount their interests so much that the manifestation of a burden in their life will, from your agentrelative perspective, be a benefit to them.

This conclusion seems repugnant. Even from the perspective of negative partiality, it is never permissible for you to let your adversaries suffer as opposed to others prosper. I can see two ways to avoid it. Firstly, we might think that, with increasing moral distance, the degree of your permitted other-sacrificing approximates zero. On this view, you would not be permitted any sacrificing at all of sufficiently distant adversaries. Alternatively, we might stipulate that it is never allowed to countenance certain

strangers than with intimates. Since this asymmetry states that your permitted self-sacrificing decreases as strangers become your intimates, Hurka and Shubert's account is likely to yield insufficiently extensive permissions to self-sacrifice your interests.

${ }^{24}$ The benefit/burden terminology intends to be making/allowing neutral. As I use the terms, when a course of action results in a burden for person $\mathrm{X}$, this does not imply that $\mathrm{X}$ is being actively interfered with or harmed. 
kinds of burdens to your adversaries. If we favour this strategy, then we have found a new reason for why a compelling defence of options must include an account of constraints. $^{25}$

\section{Accommodating Other-Sacrificing}

There are two approaches in the literature for justifying options. Only one has the resources to accommodate other-sacrificing options and their relation to other-favouring.

According to

Underivative Approaches, agent-centred options are grounded in independent and underivative permissions (as opposed to normative reasons). ${ }^{26}$

A version of this approach that I consider here says that there is a prima facie duty of beneficence for you to promote the interests of everyone impartially, but in addition to this duty, you have permissions to either pursue or not pursue your own interest. In some cases, your permissions outweigh your duty of beneficence, and this grants you options not to bring about the impartially optimal outcome. Call this the Underivative View. ${ }^{27}$

The Underivative View can accommodate other-sacrificing options by stipulating an underivative permission to not pursue your adversaries' interests. This permission can then be weighed against your duty to promote the interests of everyone impartially, and, in some cases, outweigh it, thereby rendering other-sacrificing permissible.

However, the Underivative View cannot fully account for the weight of other-sacrificing options and fails to capture the Other-Favouring/Sacrificing Asymmetry.

\footnotetext{
${ }^{25}$ See Kagan (1989), pp. 19-24, and chs. 3 and 4.

${ }^{26}$ Examples of these views Raz (1975), Gert (2004), and Hurka and Shubert (2012).

${ }^{27}$ This is Hurka and Shubert's (2012), pp. 5-10, proposed view.
} 
First, the Underivative View cannot account for the asymmetry between other-favouring and other-sacrificing at the level of partiality. It can only account for this asymmetry extensionally at the level of overall assessment by appealing to the interaction between your underivative permissions and special duties.

However, even if it opts for this strategy, it cannot account for the fact that your othersacrificing permissions become weaker as the distance between you and your adversaries increases. It can tell the following story to explain why the extensiveness of your other-favouring options decreases as you move closer to your intimates. As someone becomes closer to you in moral space, your special duty to promote their interests increases in weight. You are required to favour your good friend more than your close acquaintance. As your special duty increases in weight, it tells against your permission to favour them more. ${ }^{28}$

No analogous story can be told about the greater decrease in extensiveness of your other-sacrificing options. Three options present themselves. All of them fail.

The first is to suggest that the weight of your duty of beneficence limits the extensiveness of your permitted other-sacrificing. However, this duty does not increase in weight as your adversary becomes more of an adversary for you. It remains constant, so it cannot explain the more concave evolution of the extensiveness of your permitted other-sacrificing.

Perhaps the Underivative View can stipulate the existence of a weakened duty of beneficence to discount the interests of your enemies whose increasing weight tells against your permissions to other-sacrifice. But this implies that it can be wrong for you to give a greater benefit to your enemy as opposed to a smaller one to a stranger, which seems implausible.

\footnotetext{
${ }^{28}$ But not so much that there is overall no net increase in the extensiveness of your otherfavouring permission (see previous section).
} 
Lastly, the Underivative View might try to say that your special duty of reparations increases as the moral distance between you and your adversaries increases. As your opponent becomes an enemy, perhaps even an arch-enemy, you will have increasingly engaged in negative interactions that require you to compensate them. This means that the weight of your special duty to compensate your adversary will increase and weigh against your permission to other-sacrifice them. However, this argument presupposes that there can be no negative personal relationships with long-term adversaries that are one-directional. That seems intuitively false.

Let's consider a second approach for justifying options. According to

Reasons-based Approaches, permissions are grounded in the conflict of agentrelative and agent-neutral reasons. ${ }^{29}$

There are many different variants of reason-based views. I here consider one of the most promising frameworks.

On this Agent-Relative Reason View, you have agent-neutral reason to do what is best from the impartial perspective and agent-relative reason to do what is best form the agent-relative perspective. ${ }^{30}$ You have a permission to act impartially suboptimally in some situation just in case your agent-neutral and agent-relative reason favour conflicting courses of action. If this is the case, then you are permitted to take on either perspective and do what is either agent-neutrally or agent-relatively optimal.

${ }^{29}$ Scheffler (1982), Raz (1999), and Parfit (2011) develop the most widely known approaches.

${ }^{30}$ See Bader (forthcoming) for a defence of a decision-theoretic form of dual-ranking actconsequentialism based on this framework of normative reasons. Another dual-ranking actconsequentialism is developed by Portmore (2008). However, Portmore's view cannot justify other-sacrificing options at all given its over-commitment to the moral significance of the Self/Other Asymmetry. 
The Agent-Relative Reason View can accommodate other-sacrificing options as follows. It says that agent-relative reasons are modified agent-neutral reasons. ${ }^{31}$ The weight of your agent-relative reasons is a function of the distance in moral space between two agents. The distance between you and others in moral space is a function of your personal relationships with them. This means that you have stronger (intensified) agent-relative reason to promote the interests of your intimates who stand closer to you by virtue of your positive personal relationship with them.

By the same token, you have weaker (attenuated) agent-relative reasons to promote the interests of your adversaries who are more distant from you than strangers by virtue of your negative personal relationship with them. Other-sacrificing options are hence a result of the conflict between your agent-neutral reason to promote the interests of everyone impartially and your weakened agent-relative reason to promote the interests of your adversaries.

The Agent-Relative Reason View has the capacity to successfully account for the Other-Favouring/Sacrificing Asymmetry, but it is not clear that it can do so in a way that is not ad hoc.

It can claim that the function which intensifies the weight of your agent-neutral reasons is different from the function which attenuates them. The intensifying modification function might be more concave than the attenuating modification function. To defend this solution plausibly, it would suit the Agent-Relative Reason View well to offer an explanation as to why the modification function should take this asymmetrical form. I cannot think of one.

\section{Conclusion}

\footnotetext{
${ }^{31}$ See Bader (2016) for a detailed development of this modifier-framework.
} 
There exist other-sacrificing options. We might think that these options are in important respects asymmetrical to other-favouring options. Of the two views that I considered, I found that only one of them has the resources to accommodate other-sacrificing options as well as their structural differences vis-à-vis other-favouring options in moral space.

What are some upshots of this discussion? One is that any successful defence of options faces a more extensive task than many have acknowledged-perhaps we even have found new grounds to be sceptical about the project of defending options altogether. Another is that the domain of negative partiality deserves much more attention in ethical theorising than it has received so far. 


\section{Works Cited}

Bader, R. “Agent-relative Prerogatives and Suboptimal Beneficence.” In: Oxford Studies in Normative Ethics: Volume 9, edited by Mark Timmons. Oxford: Oxford University Press, forthcoming.

Bader, R. "Conditions, modifiers and holism." In: Weighing Reasons, edited by Errol Lord and Barry Maguire. Oxford: Oxford University Press, 2016.

Broad, C.D. "Certain Features in Moore's Ethical Doctrines." In: The Philosophy of G.E. Moore, edited by Paul Schilpp. Evanston Ill: Northwestern University Press, 1942: 41-68.

Davis, N. "Utilitarianism and Responsibility”, Ratio 22 (1980): 15-35.

Gert, J. Brute Rationality: Normativity and Human Action. Cambridge: Cambridge University Press, 2004.

Hurka T, Shubert E. "Permissions To Do Less Than the Best: A Moving Band." In: Oxford Studies in Normative Ethics: Volume 2, edited by Mark Timmons. Oxford: Oxford University Press, 2012.

Kagan, S. The Limits of Morality. Oxford: Oxford University Press, 1991.

Kamm, F. M. "Non-Consequentialism, the Person as an End-in-Itself, and the Significance of Status," Philosophy \& Public Affairs 21, no. 4 (1992): 354-89.

Kolodny, N. "Which Relationships Justify Partiality? General Considerations and Problem Cases." In Partiality and Impartiality: Morality, Special Relationships, and the Wider World, edited by Brian Feltham, and John Cottingham. Oxford: Oxford University Press, 2010.

Lange, B. The Right to Parent as a Project. (manuscript-a).

Lange, B. Permissible Partiality: Structure. (manuscript-b).

Nozick, R. Anarchy, State, and Utopia. New York: Basic Books, 1974 (2013 edition).

Parfit, D. “Innumerate Ethics”, Philosophy and Public Affairs 7 (1977-8): 285-301.

Portmore, D. "Position-Relative Consequentialism, Agent-Centered Options, and Supererogation”, Ethics, vol. 113, no. 2 (2003): 303-332. 
Portmore, D. "Dual-ranking act-consequentialism", Philosophical Studies 138 (2008): 409-427.

Raz, J. Engaging Reason: On the Theory of Value and Action. Oxford: Oxford University Press, 1999.

Scheffler, S. The Rejection of Consequentialism. Oxford: Clarendon Press, 1982.

Sider, T. “Asymmetry and Self-Sacrifice”, Philosophical Studies 70 (1993):117-132.

Slote, M. "Morality and Self-Other Asymmetry", Journal of Philosophy, (1984): 179_ 192.

Slote, M. Common-Sense Morality and Consequentialism. London: Routledge \& Kegan Paul, 1985.

Stocker, M. "Agent and other: Against ethical universalism”, Australasian Journal of Philosophy, 54:3 (1976): 206-220. 